\title{
Treatment Adherence Levels and Factors Affecting Adherence in Patients Receiving Osteoporosis Treatment
}

\author{
Turkan Pasali Kilit ${ }^{1}$ (D) Kevser Onbasi $^{2}$ (D) Filiz Ozyigit $^{3}$ \\ ${ }^{1}$ Kutahya Health Sciences University, Evliya Celebi Training and Research Hospital, Department of Internal Medicine, Kutahya, Turkey \\ ${ }^{2}$ Kutahya Health Sciences University Faculty of Medicine, Department of Endocrinology, Kutahya, Turkey \\ ${ }^{3}$ Kutahya Health Sciences University Faculty of Medicine, Department of Pharmacology, Kutahya, Turkey \\ Correspondence Author: Turkan Pasali Kilit \\ E-mail: turkandr@yahoo.com
}

Received: $04.03 .2019 \quad$ Accepted: 22.11.2019

\begin{abstract}
Objective: Treatment adherence is regarded as an important factor in achieving optimal outcomes across many disease states. The purpose of this study was to evaluate the adherence of osteoporosis patients and determinate the factors affecting adherence.

Methods: A total number of 150 patients with osteoporosis were included in the study. Demographic data, anthropometric measurements and laboratory results of the patients were recorded. In addition, the survey questions including patients' marital status, education levels, income status, smoking and alcohol consumption habits, exercise levels, dietary habits, fracture histories, menopausal ages, treatments they received, medication side effects and treatment adherences were asked by a face-to-face interview method.

Results: The mean age of the 150 patients included in the study was $65.6 \pm 9.8$ years. Ninety-four percent of the patients were female. Patients who received osteoporosis treatment with oral agents had poorer adherence to treatment than patients receiving subcutaneous or intravenous agents $(p=0.003)$. Other factors had no effect on adherence.

Conclusion: Treatment adherence, which is one of the concepts related to the principles of rational drug use, is an important part of treatment success. The choice of agents administered subcutaneously or intravenously in the treatment of osteoporosis will result in better adherence with treatment than oral agents.
\end{abstract}

Keywords: Osteoporosis, adherence, bisphosphonate

\section{INTRODUCTION}

Adherence to therapy means that the patient obeys to the rules of treatment and is also active involved in this process. Rational drug use rules begin with diagnosis and prescription. It goes on with patient education and continuing with the drug. Rational drug therapy means therapy with appropriate dosage in appropriate form also in the appropriate range with appropriate intervals. Adherence is determined whether the patient uses the medicaments in direction of recommendations of the physician. If there is a problem in the name of adherence there cannot be told about therapy success (1).

Osteoporosis is a disease that can be seen in every part of the society and every age, and it has to be considered from physical, psychological and economic aspects. When addressed in terms of gender, $80 \%$ is more common in women. This is why it is generally evaluated as a health problem for women (2-4). The deterioration of the bone structure in addition to low bone mass in osteoporosis causes morbidity and mortality by preparing the ground for fracture formation. Osteoporosis due to prolonged life span is defined as a bone disease, which is seen in elderly individuals, and due to its multifactorial, insidious course, and long treatment duration, and chronic course, early diagnosis and treatment yields successful results (5-7). Currently, classification of osteoporosis as primary or secondary due to the etiology is a widely accepted classification, although a wide range of various classifications. Primary osteoporosis can be agerelated (senile) or idiopathic, with no known disease or event that can cause osteoporosis. Osteoporosis is defined as secondary osteoporosis if it develops due to diseases such as malign, endocrine, rheumatologic, digestive or respiratory diseases. Inactivity, smoking, alcohol consumption and drug use are also considered as causes of secondary osteoporosis (8).

If pharmacological treatment of osteoporosis is carried out within the framework of rational drug use principles in a cost-effective manner and in a convenient way of current scientific towards, it is possible to achieve multi-faceted benefits by preventing both fracture formation and disease progression. In our study, we aimed to determine the level 
of adherence of our patients to osteoporosis treatment and also the affecting factors.

\section{METHODS}

\section{Study population}

The study was designed as a descriptive, cross-sectional, survey study. The study was carried out on face-to-face interviews with 150 patients, who consecutively attended our Internal Disease and Endocrinology outpatient clinics at our hospital from September to November in the last year. Patients who had been diagnosed with osteoporosis and had been receiving osteoporosis treatment already were included in the study. Exclusion criteria included patients with any history of chronic renal failure, malabsorption syndrome, liver and biliary system diseases, active infection, cancer, chronic inflammatory diseases involving the skeletal system, advanced heart failure, and permanent immobility. In the data collection form, forms of fracture, nutrition habits of milk and dairy products, drugs used for osteoporosis, forms of osteoporosis drugs (oral, intravenous, subcutaneous), application frequency and duration, application methods (intermittent or continuous) were recorded as well as sociodemographic information. Concomitant diseases and drug use policies for these diseases were questioned. Patients were re-interviewed 3 months later and patients were reevaluated for drug side effects and drug interactions. At the same time, patients' treatment adherence (leaving the treatment in place, forgotten treatment) was assessed. Written informed consent was obtained from all of the patients prior to the inclusion into the study. Our study complies with the 1964 World Health Organization Declaration of Helsinki and the World Psychiatric Association, Good Clinical Practices and Good Laboratory Practice Rules. Dumlupınar University Faculty of Medicine, Clinical Research Ethics Committee approved the study protocol (Approval number is 201711/3).

\section{Statistical analysis}

The data obtained in the study were analyzed using the Statistical Program for Social Sciences (SPSS) version 22.0 (SPSS Inc., Chicago, IL, USA). Normal distribution of continuous variables was evaluated by Kolmogorov-Smirnov and Shapiro-Wilk tests. For parametric tests, continuous variables are expressed in mean \pm standard deviation, while for non-parametric tests, data are expressed in median and interquartile range $\left(25^{\text {th }}\right.$ and $75^{\text {th }}$ percentiles). Differences between groups were compared using Student's t test for normally distributed data. Categorical parameters were analyzed using Chi-square test. A $p$ value of $<0.05$ was considered statistically significant.

\section{RESULTS}

Sociodemographic characteristics of the patients, exercise habits, levels of attention to nutrition, cigarette and alcohol consumption habits are shown in Table 1 . The age of the participating patients ranged from 42 to 88 years and the mean age was $65.6 \pm 9.8$ years. The $93.3 \%$ of the patients in the study group constituted of female individuals. Patients had a fracture of 41 variable fractures, of which 26 were vertebrae and 6 were hip fractures.

Table 1. Sociodemographic characteristics of the study groups

\begin{tabular}{|c|c|}
\hline & $n=150$ \\
\hline Age, year & $65.6 \pm 9.8$ \\
\hline Female gender, $\mathrm{n}(\%)$ & $140(93.3 \%)$ \\
\hline $\begin{array}{l}\text { Marital status, } \mathrm{n}(\%) \\
\text { Married } \\
\text { Single } \\
\text { Divorced/Widowed }\end{array}$ & $\begin{array}{c}111(74.0 \%) \\
1(0.7 \%) \\
38(25.3 \%)\end{array}$ \\
\hline $\begin{array}{l}\text { Educational status, } \mathrm{n}(\%) \\
\text { Illiterate } \\
\text { Primary school graduate } \\
\text { Secondary school graduate } \\
\text { High school graduate } \\
\text { University graduate }\end{array}$ & $\begin{array}{c}46(30.7 \%) \\
89(59.3 \%) \\
5(3.3 \%) \\
8(5.3 \%) \\
2(1.3 \%)\end{array}$ \\
\hline $\begin{array}{l}\text { Income status (monthly, Turkish Liras), n (\%) } \\
\text { Less than } 1000 \\
1000-1500 \\
1500-2500 \\
2500-3500 \\
3500-5000 \\
\text { More than } 5000\end{array}$ & $\begin{array}{c}19(12.7 \%) \\
87(58.0 \%) \\
36(24.0 \%) \\
5(3.3 \%) \\
2(1.3 \%) \\
1(0.7 \%)\end{array}$ \\
\hline $\begin{array}{l}\text { Bone fracture, } n(\%) \\
\text { Vertebra } \\
\text { Hip } \\
\text { Wrist } \\
\text { Arm } \\
\text { Ankle } \\
\text { Knee } \\
\text { Hand }\end{array}$ & $\begin{array}{c}41(27.3 \%) \\
26 \\
6 \\
4 \\
2 \\
1 \\
1 \\
1\end{array}$ \\
\hline T score hip & $-1.84 \pm 1.11$ \\
\hline T score L1-L4 vertebra & $-3.13 \pm 0.52$ \\
\hline T score femur neck & $-2.08 \pm 0.98$ \\
\hline $\begin{array}{l}\text { Exercise, } \mathrm{n}(\%) \\
\text { Less than } 3 \text { times per week } \\
3 \text { times weekly } \\
\text { More than } 3 \text { times weekly }\end{array}$ & $\begin{array}{c}62(41.3 \%) \\
29 \\
16 \\
17\end{array}$ \\
\hline $\begin{array}{l}\text { Paying attention for nutrition, } \mathrm{n}(\%) \\
\text { Milk and dairy products } \\
\text { Soup prepared with bones } \\
\text { Honey }\end{array}$ & $\begin{array}{c}79(52.7 \%) \\
77 \\
1 \\
1\end{array}$ \\
\hline Smoker, n (\%) & $15(10.0 \%)$ \\
\hline Alcohol consumption, n (\%) & $0(0 \%)$ \\
\hline Height, cm & $156.1 \pm 6.7$ \\
\hline Weight, kg & $68.2 \pm 11.8$ \\
\hline Body mass index, $\mathrm{kg} / \mathrm{m}^{2}$ & $28.0 \pm 4.7$ \\
\hline Menopause age, year & $45.4 \pm 7.2$ \\
\hline Vitamin D level (ng/ml) & $25(19-36)$ \\
\hline
\end{tabular}

The majority of drugs used for the treatment of osteoporosis were drugs in the bisphosphonate group ( $n=123,82 \%)$ (Figure 1). 


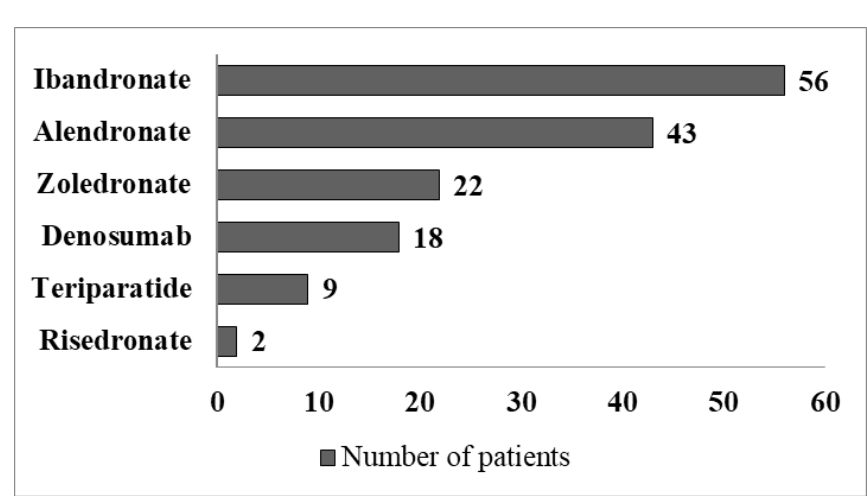

Figure 1. Drugs used in the treatment of osteoporosis.

Ninety-one $(60.7 \%)$ of the patients treated with osteoporosis were receiving oral medications, while 32 patients $(21.3 \%)$ used their drugs via the intravenous route and 27 patients $(18 \%)$ via the subcutaneous route. When we examined the conditions of the patients who forgot their treatment, 20 of the 34 patients who forgot their treatment were using oral medication for osteoporosis. The rate of forgetting treatment of patients using oral medication was significantly higher than those using intravenous or subcutaneous administration $(p=0.003)$. When we examine the relationship between the drug use form and the break period; we have found that 61 patients were on breaks for treatment and 41 patients who made breaks most frequently used oral medications $(p=0.359)$.

One of the indicators of the adherence behavior is the usage of medicaments in accordance to the instruction rules. Among the patients who received their osteoporosis treatment via the oral route; all the 91 patients were taking their drug appropriately in the morning, but 12 of them was using the drug falsely after breakfast.

The waiting period ranged from 10 to 120 minutes after taking the medicine, while 78 patients were waiting and 13 patients were not waiting. After taking the medication, 70 patients stated that they were standing upright, while 21 patients were not standing upright.

Thirty five patients (23.3\%) reported side effects due to drug treatment. The most common side effect was dyspepsia. Other common side effects were; dysphagia, nausea, vomiting and headache. Seventy four patients (49.3\%) were on medication for gastrointestinal system (GIS) side effects. The drugs used are shown in Table 2. No significant drug interaction was observed in the patients.

Table 2. Drugs used for the gastrointestinal system side effects

\begin{tabular}{|l|c|}
\hline Drugs & $\mathbf{n = 7 4}$ \\
\hline Lansoprazole & 49 \\
\hline Esomeprazole & 8 \\
\hline Rabeprazole & 7 \\
\hline Pantoprazole & 7 \\
\hline Nizatidine & 1 \\
\hline Famotidine & 1 \\
\hline $\begin{array}{l}\text { Sodium alginate + sodium bicarbonate }+ \\
\text { calcium carbonate }\end{array}$ & 1 \\
\hline
\end{tabular}

When the measures taken by osteoporosis patients in their homes against falls were examined, only 24 patients (16\%) took measures. The measures that had been taken were; take measures to prevent carpet slipping (13 patients), not going to high stairs (8 patients), using a walking stick or walker (2 patients), and lifting mats in the house (1 patient).

Family support for any disease is important. When we examined the marital status of the patients in our study group, 111 (74\%) patients were married, 1 (0.7\%) were single, and 38 (25.3\%) were divorced or widows. Family support was available in 132 (88\%) of the study patients. When we examine the cases of patients with family support who discontinue treatment and forget treatment; we observed that 54 out of 61 patients who had discontinued treatment had family support ( $p=0.870)$. We also found that 32 out of 34 patients who forgot the treatment had family support $(p=0.342)$. Although there was a positive family support in the patients in our study group, there was a drug adherence problem.

The average age of our study group is $65.6 \pm 9.8$ years; we can say it as an elderly population group. Therefore most of the patients have comorbidities and were taking multiple medications. The most common diseases in patients are hypertension, diabetes mellitus and hyperlipidemia (Table 3). Patients receiving polypharmacy (3 or more drugs) were significantly elder than patients who did not receive polypharmacy $(67.50 \pm 9.01$ years versus $62.47 \pm 10.43$ years respectively, $p=0.003$ ). Forgetting rate of osteoporosis medicaments were similar among patients receiving polypharmacy and above them who did not receive polypharmacy treatment ( $20 \%$ to $18 \%$ respectively, $\mathrm{p}=0.476$ ). Treatment break rates of patients receiving polypharmacy were similar to those who did not $(p=0.086)$. There were 34 patients who forgot the treatment, and the mean age was similar to the mean age of the patients who did not forget the treatment $(65.2 \pm 9.8$ years versus $65.4 \pm 9.8$ years respectively, $p=0.922$ ). All 34 patients who forgot their treatment were female when the gender relation was examined. There was no difference between treatment forgetting and patients' income status $(p=0.464)$, also no difference between treatment forgetting and educational status could be observed $(p=0.922)$. There were 61 patients who made breaks in the treatment and the mean age was similar to the mean age of the patients who did not interrupt their treatment $(67.2 \pm 9.3$ years versus $64.5 \pm 10.0$ years respectively, $p=0.101)$. When the gender relationship with the therapy intervention was examined, 59 of 61 patients were female and there was no difference in terms of gender $(p=0.168)$. There were no differences between the treatment interventions and the income status of the patients $(p=0.901)$ and education status $(p=0.220)$.

Six percent of the patients who were treated with osteoporosis were using also herbal support products or had Hijama treatment as complementary medicine. 


\section{DISCUSSION}

Drug adherence rates for chronic diseases range from $50 \%$ to $60 \%$. Values below this ratio are considered as low treatment adherence. Among the factors leading to this are the asymptomatic course of the disease and the high incidence of side effects due to treatment (9). Osteoporosis is an insidious illness. There are various side effects of the drugs used for its treatment. In our study, the incidence of side effects related to drugs used in the treatment of osteoporosis was found to be $23.3 \%$ and the treatment interruption rate was $40 \%$. Our patients can be considered as to have some drug adherence problems.

Osteoporosis is a sneaky and preventable disease seen in both sexes, but is more common among women. With increasing age, the incidence of osteoporosis is also increasing. The incidence of osteoporosis is higher in women, especially in postmenopausal period (3). According to prevalence studies, the prevalence of osteoporosis in our country was found to be $7.5 \%$ in males older than 50 years and $12.9 \%$ in females (24). When we look at the sex and age distribution of our study group, we can say that the average age is 65 years and the majority is female patients. Behavioral changes and lifestyle changes can change the course of the disease positively by identifying early risk factors for osteoporosis (10). Smoking, sedentary lifestyles, not to consume regular milk and dairy products are some of the risky habits for osteoporosis. Smoking is an important risk factor for osteoporosis and fracture formation. The relationship between smoking and osteoporosis is due to the harmful effects of nicotine in majority (11). Fortunately, smoking rates of our patients were low.

One important issue in preventing osteoporosis is regularly exercising (12). In a study conducted by Yağmur $\mathrm{Y}, 96.2 \%$ of the women did not exercise regularly, although a large proportion of them had adequate knowledge of osteoporosis (13). In another study has been shown that $51.2 \%$ of the patients did never exercise (14). Although the rate of exercising in our study group is low, it can be considered as good if compared with the data of previous studies. According to the Framingham study, consumption of milk and dairy products is associated with increased hip bone density, but not with spinal cord density and fracture development (10). It is known that women do not consume enough milk and dairy products during adolescence and adulthood. Patients' habits not to consume milk and dairy products were found to be $47.3 \%$. The low consumption of milk and dairy products in women in our society is among the factors that prepare the osteoporosis background (10). Hyperthyroidism, diabetes, rheumatoid arthritis, chronic obstructive pulmonary disease, asthma, some renal diseases, malabsorption syndrome and chronic diarrhea are the causes of the development of secondary osteoporosis (15). A lot of our patients had also concomitant diseases that may also contribute to the development of osteoporosis.

Long-term use is required for effective treatment with bisphosphonates. Bisphosphonates have forms that are applied on a daily, weekly, monthly or annual basis. However, investigations show that $70 \%$ of daily drug users and $60 \%$ of weekly drug users terminate treatment before the end of one year of treatment (16). In other words, as the usage period is more frequent, there is a bigger adherence problem. In our study group, the bisphosphonate group included patients receiving their medications daily, weekly, monthly, every six months and once a year. When we examine the drug forms (oral, intravenous, subcutaneous) of our patients using bisphosphonates, we can say that treatment forgetting and treatment interruption are seen most frequently in patients taking oral medications. Of the patients using oral bisphosphonate, 41 were using bisphosphonates orally once a week and 50 patients once per month.

Side effects that occur in patients using bisphosphonates in the clinic are often seen as GIS complaints. The incidence of side effects related to the use of bisphosphonates in our study was $23.3 \%$. Side effects were mainly stomach pain, swallowing difficulty, nausea, vomiting and headache. Proton pump inhibitors (PPI) are preferred to prevent and treat the development of GIS-mediated side effects. Among the causes of secondary osteoporosis are also mentioned the use of drugs. PPI can also be mentioned as one of these drugs. PPI's, produced as benzimidazole derivatives, act by reducing the release of gastric acid. In recent years, research has been published on the effects of PPI on calcium malabsorption and on the development of osteoporosis and fracture formation. It is stated that fractures developed due to the use of PPI are most commonly in the hip and spine, and the dose and duration are important, and it is stated that only one year of use is sufficient for the development of osteoporosis (17). In our study, we found that 24 of 71 patients who had used PPI for GIS complaints had a history of fracture. The most common observed fracture was vertebra fractures $(n=14)$.

There are different opinions in the literature regarding the relationship between treatment adherence and education level. In an adherence study for calcium and vitamin D treatment, it is reported that the education level of incompatible patients is low, whereas in another study there is no relation between education level and drug adherence $(18,19)$. The $59.3 \%$ of our study group had only education at primary education level. We have observed that drug adherence is lower among less educated patients and, the rate of intermittent breaks of treatment dramatically decreases as education level increases. Forgetting of the treatment was much lower among the more educated group. According to our study results, we can say that drug adherence is high in educated osteoporosis patients, while drug adherence is lower in low educated patients.

Altered physiology in elderly individuals may lead to some problems related to drug use and adherence. The use of multiple medicines in elderly people leads to the frequent occurrence of increased side effects, in particular the problem of forgetting the treatment, and the interruption of treatment (20). All of these problems are present in our study group and are similar to previous studies. 
In studies related to adherence, it is pointed out that family support affects the treatment positively. There are opinions that the level of adherence is low in individuals living alone (21). Most of the patients in our study had family support, but the drug adherence problem was also observed in individuals with family support. In long-term treatments, drug adherence was found to be related to the developmental level of the countries also. In developed countries, adherence to the drug was observed in half of the population, while lower levels were found in less developed countries (22). Cramer et al. reported an annual treatment adherence rate to the drug was $26 \%$ to $70 \%$ in osteoporosis (23). Solomon et al. and Penning et al. reported an adherence rate of $50 \%$ (24, 25). According to our data, drug adherence rate is moderate in our study population.

\section{CONCLUSION}

In conclusion, the factors that affect adherence to the treatment of osteoporosis in our study were interrupting the drug treatment, forgetting to take the medication, disregarding to obey to medication instructions (not taking the pill on fasting, not standing up after taking the drug) and multiple drug use. This was especially observed in patients receiving oral bisphosphonates. $49.3 \%$ of the patients, nearly the half of patients were on medication for GIS side effects of oral bisphosphonates, which itself causes osteoporosis. This is also increases the treatment costs and brings also another additive drug. Our suggestions for solutions to the drug adherence in the directions of rational drug use is intelligent planning of osteoporosis treatment, implementation and follow-up of osteoporosis treatment, efforts for patient trainings, strengthening patient-doctor communication and raising awareness of osteoporosis.

\section{REFERENCES}

[1] Toklu HZ, Akıcı A, Keyer Uysal M, Ayanoğlu Dülger G. The role of the doctor and pharmacist in improving patient adherence in the process of rational drug use. Türk Aile Hek Derg 2010; 14:139-145 (In Turkish).

[2] Warriner AH, Saag KG. Osteoporosis diagnosis and medical treatment. Orthop Clin North Am 2013; 44:125-135.

[3] Tella SH, Gallagher JC. Prevention and treatment of postmenopausal osteoporosis. J Steroid Biochem Mol Biol 2014; 142:155-170.

[4] Tuzun S, Eskiyurt N, Akarirmak U, Saridogan M, Senocak M, Johansson H, Kanis JA. Turkish Osteoporosis Society. Incidence of hip fracture and prevalence of osteoporosis in Turkey: the FRACTURK study. Osteoporos Int 2012; 23:949-955.

[5] Khan AA, Hanley DA, Bilezikian JP, Binkley N, Brown JP, Hodsman $A B$, Josse RG, Kendler DL, Lewiecki EM, Miller PD, Olszynski WP, Petak SM, Syed ZA, Theriault D, Watts NB; Canadian Panel of the International Society for Clinical Densitometry. Standards for performing DXA in individuals with secondary causes of osteoporosis. J Clin Densitom 2006; 9:47-57.

[6] Alejandro P, Constantinescu F. A Review of Osteoporosis in the Older Adult: An Update. Rheum Dis Clin North Am 2018; 44:437-451.
[7] Assessment of fracture risk and its application to screening for postmenopausal osteoporosis. Report of a WHO Study Group. World Health Organ Tech Rep Ser 1994; 843:1-129.

[8] Mosekilde L, Vestergaard P, Rejnmark L. The pathogenesis, treatment and prevention of osteoporosis in men. Drugs 2013; 73:15-29.

[9] McCombs JS, Thiebaud P, McLaughlin-Miley C, Shi J. Compliance with drug therapies for the treatment and prevention of osteoporosis. Maturitas 2004; 48:271-287.

[10] Sahni S, Tucker KL, Kiel DP, Quach L, Casey VA, Hannan MT. Milk and yogurt consumption are linked with higher bone mineral density but not with hip fracture: the Framingham Offspring Study. Arch Osteoporos 2013; 8:119.

[11] Jaramillo JD, Wilson C, Stinson DS, Lynch DA, Bowler RP, Lutz S, Bon JM, Arnold B, McDonald ML, Washko GR, Wan ES, DeMeo DL, Foreman MG, Soler X, Lindsay SE, Lane NE, Genant HK, Silverman EK, Hokanson JE, Make BJ, Crapo JD, Regan EA. COPDGene Investigators. Reduced Bone Density and Vertebral Fractures in Smokers. Men and COPD Patients at Increased Risk. Ann Am Thorac Soc 2015; 12:648-656.

[12] Borer KT. Physical activity in the prevention and amelioration of osteoporosis in women: interaction of mechanical, hormonal and dietary factors. Sports Med 2005; 35:779-830.

[13] Yağmur $Y$. Evaluation of the Efficiency of the Health Improvement Program Administered on Young Women for Protection of Osteoporosis. İnönü Üniversitesi Tıp Fakültesi Dergisi 2006; 134:257-262 (In Turkish).

[14] Kılıç D, Erci B. The Impact of the Planned Health Education Given to Premenoposal Women on the Osteoporosis Health Beliefs and Knowledge Levels. Journal of Anatolia Nursing and Health Sciences 2007; 10:34-44 (In Turkish).

[15] Üstündağ N, Korkmaz M, Öksüzkaya A, Balbaloğlu Ö, Karataş Eray I. Classification of Osteoporosis, Determining Risk Factors and One Minute Osteoporosis Risk Test. Euras J Fam Med 2013; 2:107-114.

[16] Gonnelli S, Masi L, Brandi ML, Nuti R. Implementing adherence to osteoporosis treatments. Clin Cases Miner Bone Metab 2009; 6:193-196.

[17] Madanick RD. Proton pump inhibitor side effects and drug interactions: much ado about nothing? Cleve Clin J Med 2011; 78:39-49.

[18] Castelo-Branco C, Cortés X, Ferrer M. UNICAD study investigators. Treatment persistence and compliance with a combination of calcium and vitamin D. Climacteric 2010; 13:578-584.

[19] Vytrisalova M, Blazkova S, Palicka V, Vlcek J, Cejkova M, Hala T, Pavelka K, Koblihova H. Self-reported compliance with osteoporosis medication-qualitative aspects and correlates. Maturitas 2008; 60:223-229.

[20] Gokce Kutsal Y, Barak A, Atalay A, Baydar T, Kucukoglu S, Tuncer T, Hizmetli S, Dursun N, Eyigor S, Saridogan M, Bodur H, Canturk F, Turhanoglu A, Arslan S, Basaran A. Polypharmacy in the elderly: a multicenter study. J Am Med Dir Assoc 2009; 10:486-490.

[21] Col N, Fanale JE, Kronholm P. The role of medication noncompliance and adverse drug reactions in hospitalizations of the elderly. Arch Intern Med 1990; 150:841-845.

[22] Van Wijk BL, Klungel OH, Heerdink ER, de Boer A. Effectiveness of interventions by community pharmacists to improve patient adherence to chronic medication: a systematic review. Ann Pharmacother 2005; 39:319-328. 
[23] Cramer JA, Gold DT, Silverman SL, Lewiecki EM. A systematic review of persistence and compliance with bisphosphonates for osteoporosis. Osteoporos Int 2007; 18:1023-1031.

[24] Solomon DH, Avorn J, Katz JN, Finkelstein JS, Arnold M, Polinski JM, Brookhart MA. Compliance with osteoporosis medications.
Arch Intern Med 2005; 165:2414-2419.

[25] Penning-van Beest FJ, Goettsch WG, Erkens JA, Herings RM. Determinants of persistence with bisphosphonates: a study in women with postmenopausal osteoporosis. Clin Ther 2006; 28:236-242. 